\title{
LA REESTRUCTURACION DE LA GRAN INDUSTRIA Y LOS PROCESOS SOCIOPOLITICOS EN LA CIUDAD: TURIN, POR EJEMPLO
}

\section{Arnaldo Bagnasco}

Las fábricas están cambiando rápidamente. Cambian las estrategias de inversión de las empresas, las tecnologías aplicadas a las máquinas, la división del trabajo, la localización. A fines de la década de 1960, las grandes empresas empezaban a asfixiarse: las dificultades a que se enfrentaban podrían definirse como problemas de adaptación a un ambiente social y económico que se había vuelto más inestable y turbulento. Sectores enteros entraban en crisis mientras que, en las nuevas condiciones, recuperaban terreno de acción unidades de dimensiones más reducidas. En general se empezó a experimentar, por el sistema de ensayo y error, con nuevas formas de organización. Ahora que la situación empieza a verse más clara, nos damos cuenta de que áreas otrora caracterizadas por un alto grado de desarrollo han sido abandonadas por la industria, de que han surgido rápidamente nuevos distritos industriales en regiones que jamás habian manifestado una especial vocación en este sentido y de que, como quiera que sea, la anterior distribución ha sido objeto de profundas redefiniciones.

Turín es un ejemplo de entramado de grandes industrias que se ha reestructurado para adaptarse a las nuevas circunstancias sin trasladarse a otro enclave. Recurriendo a una metáfora, la fábrica no ha dejado la ciudad. Es decir, que no se ha producido una desindustrialización, y, por lo tanto, la sociedad que está emergiendo de la crisis no es una sociedad marginada. Se trata

\section{RểS}


más bien de una sociedad dividida que lleva en su seno los signos y la cultura de la nueva organización social de la producción unidos a los problemas sociales que trajo consigo la redefinición. Se trata de procesos en curso que están complicando el panorama tradicional de la sociedad turinesa y modificándolo sustancialmente. Si volvemos la vista al pasado nos damos cuenta de que la imagen de la ciudad-fábrica, aunque en decadencia, tenía cierta consistencia. Mirando hacia el futuro, quizá resulte más fácil empezar a pensar en la ciudad y la fábrica, lo cual no significa en modo alguno que la gran industria haya dejado de ser la piedra de toque de la economía.

En este artículo trataremos de echar luz sobre las transformaciones de la organización de la industria y, a continuación, intentaremos ver algunas consecuencias de las mismas sobre la organización social e institucional. No tenemos en mente procesos lineales de causa-efecto. Se trata más bien de esbozar un panorama en el cual tendrán que moverse en el futuro los actores sociales.

\section{Una visión de conjunto}

No se puede pensar en la industria turinesa haciendo referencia únicamente a la Fiat. Sin embargo, el peso de la metalurgia en el conjunto de la industria, y del sector del automóvil dentro de la mecánica, están fuera de toda duda.

En 1981, la metalurgia empleaba casi al 63 por 100 de todos los que trabajaban en la industria en la provincia; y los empleados en el sector del automóvil representaban el 42 por 100 de los que trabajan en la metalurgia. En cifras absolutas, la industria mecánica emplea alrededor de 304.000 personas, y la industria del automóvil a unos 127.000 trabajadores. Como puede verse, el peso relativo de las distintas ramas de la industria no ha cambiado demasiado. Como quiera que sea, el peso de la industria metalúrgica ha crecido, aunque poco, aumentando las particularidades de la zona: en la provincia de Turín, el sector tiene, sobre el conjunto de la industria, un peso casi seis veces superior al que tiene en el resto del país. Es de destacar también que el aumento de la cuota de la mecánica sobre el total de la industria local se produce en el marco de una tendencia de reducción de la ocupación generalizada $y$, por lo tanto, significa una disminución relativamente menor de sus efectivos: en cifras absolutas, 9.000 ocupados menos en diez años.

En el interior de la industria manufacturera encontramos, en orden decreciente de importancia, el sector del automóvil, el de los productos de metal, el de las máquinas, el del material eléctrico y electrónico, el de las máquinas de oficina y ordenadores. En términos generales, los datos porcentuales indican la mayor o menor importancia de un sector, pero hay que tomarlos con pinzas, sobre todo en lo que hace al significado de los incrementos, ya que en esta fase están en curso importantes reestructuraciones tecnológicas, y una 
variación relativa del número de los empleados podría no significar una modificación paralela del peso del sector para otros indicadores. De todos modos, algunas industrias parecen perder terreno: las industrias de extracción y afines (pero no mucho las químicas específicamente) y las textiles. Es escasa la repercusión en los sectores típicos de la industria ligera, como el vestido, el calzado, la madera, el mueble, que han caracterizado al desarrollo de de economía difusa de las regiones de la Italia centro-nororiental a lo largo de los veinte últimos años. Además del sector del automóvil, del que ya hemos hablado, la región turinesa está especializada de una manera importante, dentro del contexto nacional, en la producción de máquinas para oficina y para la elaboración de datos: casi cuatro veces el valor medio. Siguen a ésta la especialización de la goma y de los materiales plásticos, los instrumentos de precisión, la construcción de máquinas, los productos de metal y los materiales eléctricos y electrónicos.

La importancia de la Fiat en la economía turinesa sobrepasa con mucho a lo que sugieren las cifras citadas sobre el sector del automóvil. Es preciso tener directamente en cuenta otras producciones más o menos vinculadas, y el sistema de proveedores y subcontratistas, por no hablar de las influencias indirectas sobre otros sectores, por ejemplo sobre el sector terciario, y sobre la propia evolución del entramado urbano. Además, las referencias al grupo Fiat no tienen en cuenta las conexiones financieras que, en un nivel más abstracto, se establecen a través del IFI, la financiera de la familia Agnelli.

Una reciente investigación sobre el sector de las piezas para vehículos automotores de Piamonte ha contabilizado algo menos de 500 empresas, con un total aproximado de 78.000 trabajadores, excluyendo a las que tienen hasta 10 empleados ${ }^{1}$. Casi todas estas empresas están en la provincia de Turín. Promediando la década de 1970, cuando todavía no estaba en marcha el proceso de innovación tecnológica que disminuiría, de una manera drástica, el número de los ocupados en las fábricas, aunque no el peso de la Fiat en Turín, tan sólo la planta de Mirafiori ocupaba a más de 60.000 operarios en un área de 2.500 metros cuadrados. Tomando en cuenta los establecimientos de producción de automóviles y, además, en conjunto, las producciones siderúrgicas, de autocares, de motores, de motores de aviación, de máquinas herramientas y aun otros, se llega a una cifra total de más de 135.000 empleados en la producción de Fiat tan sólo en el área de Turín. En 1975, esta cifra respondía, grosso modo, a la población de ciudades como Perugia y Rávena, y sólo 25 capitales de provincia tenían una población superior a esta cifra. Así, pues, es lícito mantener la imagen de one company town de Turín como punto de partida para un análisis que se plantee el problema de la organización social de la economía.

1 A. EnRIETri y M. Follis, «Il settore dei componenti per autoveicoli», en Politica ed Economia, núm. 5, 1983. 
Para ello será necesario preparar de antemano algunos instrumentos conceptuales que habrán de utilizarse en el análisis. Optaremos por enfocar la cuestión desde el punto de vista de los mecanismos reguladores de la economía.

\section{La organización regula la economia: la fase fordista}

En general se han estudiado los caracteres sociológicos del desarrollo económico en relación con el proceso de diferenciación estructural. En las sociedades simples y arcaicas no es posible distinguir las relaciones económicas del conjunto de las demás relaciones sociales; la economía está, por así decirlo, siempre en el interior de otras instituciones; en esos casos funciona el mecanismo de la reciprocidad, que se refiere a reglas de intercambio de contenido económico no explicitado y no tratado como tal.

En las sociedades contemporáneas, la reciprocidad caracteriza a las relaciones familiares y amistosas y a ciertas formas de relación comunitaria. Fuera de casos como éstos, se requieren técnicas específicas de regulación. La diferenciación entre la economía y el resto de la sociedad se realiza por lo general con la constitución de un sistema de acción especializado, regulado esencialmente por el mercado, en el cual las opciones de producción y de consumo son orientadas por precios fijados en contrataciones formalmente libres. Sin embargo, el ulterior desarrollo económico ha asistido al crecimiento de la función reguladora de otros mecanismos. Especialmente el desarrollo de la producción masiva a bajo costo, con la fuerte y rígida inversión de capital que esto implica, ha hecho necesaria la eliminación de inseguridades en los procesos de producción en los mercados de abastecimiento, salida de productos y trabajo. La empresa, con el crecimiento dimensional, tiende a incorporar, regulándolas por medio de la organización, funciones y relaciones previamente excluidas: la mano invisible del mercado deja lugar a la mano visible de la organización. Al mismo tiempo, ya sea como consecuencia del cambio progresivo de las condiciones sociales, ya como resultado de deficiencias reguladoras del mercado en las nuevas condiciones, han aumentado progresivamente y han adquirido un carácter más orgánico las intervenciones políticas sobre la economía; o sea, que mientras en el plano microeconómico crecía la regulación organizadora, en el macroeconómico se proponían objetivos de plena ocupación y de equidad social, perseguidos con políticas de regulación vinculadas al gasto público, comprometido, a su vez, en el desarrollo de sistemas de welfare state. Un mayor papel del Estado significa, a su vez, dos cosas: aumento de la regulación organizadora, a través de la burocracia; desarrollo del mecanismo de intercambio político, expresión con la cual se designa aquí el proceso específico a través del cual, por un lado, se protegen intereses de grupo y, por otro, se mantienen identidades y lealtades políticas; se trata, pues, de las 
relaciones típicas del proceso político moderno a través de las cuales se persiguen proyectos y fines más generales con adaptaciones pragmáticas y contrataciones entre actores diferenciados. Desde el punto de vista que hemos adoptado, el desarrollo trajo aparejado, pues, un drástico replanteamiento de las relaciones de reciprocidad, favoreciendo combinaciones reguladoras del mercado, organización e intercambio político, variables en el tiempo y en el espacio. Hemos identificado, pues, cuatro mecanismos de regulación, pero también hemos considerado ya de una manera implícita que un sistema económico está siempre regulado por una mezcla de diferentes mecanismos que sólo pueden aislarse por abstracción ${ }^{2}$.

Volvamos, entonces, a la industria turinesa y, en especial, a su núcleo, la industria del automóvil. Indudablemente, la Fiat debe enfrentarse a competidores muy aguerridos. El crecimiento de las cuotas de mercado, los acuerdos entre productores y otras estrategias no cambian sustancialmente el hecho de que, ante todo, el mercado regula las relaciones económicas en el contexto mundial. Es así como todo lo que acontece en los mercados mundiales del automóvil se refleja de una manera directa, y con grandes consecuencias, en Turín; pero lo que a nosotros nos*importa ahora es considerar que, al contrario de lo que sucede en el exterior, en el interior del sistema productivo del automóvil no es el mercado, sino la organización el principal mecanismo regulador de las relaciones económicas. Por cuanto haremos especial referencia a la dualidad mercado-organización, conviene aclarar que, en un sentido más abstracto, se puede decir que también el mercado «organiza» las relaciones sociales. De hecho, en la ciencia contemporánea existen dos conceptos opuestos (pero no contradictorios) de organización: «el de organización "estadística", creada por comportamientos individuales que no implican una referencia al régimen global por ellos generado, y el de organización "intencional", que resulta de un cálculo hecho en función de una finalidad, de una evaluación de los medios, de una estimación de las ventajas y de las desventajas» ${ }^{3}$. En el nivel en que nosotros nos hemos situado, la organización es precisamente un típico proceso intencional que da lugar a un sistema de relaciones basado en las posibilidades de control directo de un conjunto suficiente de condiciones con miras a la realización de finalidades limitadas prefijadas. En cambio, el modo en que el mercado «organiza» las relaciones globales de los actores que interactúan es típicamente probabilista: en realidad, las acciones se combinan en resultados finales a través de un mecanismo que no controlan directamente los propios actores. Esta diferencia precisamente se expresa por la metáfora de la mano

${ }^{2}$ Sobre los cuatro mecanismos de regulación y sobre el uso de esta tipología como «manera de entrar» en el estudio de los procesos sociales de la economía, véase A. BAGNASCo, «La costruzione sociale del mercato. Strategie d'impresa e esperimenti di scala in Italia», en Staţo e Mercato, núm. 13, 1985.

3 I. Prigogine y I. Stengers, voz «Organizzazione», en Enciclopedia Einaudi, vol. X, Turín, 1980. 
invisible y de la mano visible. Insistimos, sin embargo, con otras palabras, en que «estos dos extremos son opuestos, pero no contradictorios: probablemente, los sistemas sociales se sitúan todos en la zona intermedia que los separa» ${ }^{4}$.

El gran desarrollo de la Fiat comienza con la decisión de «hacer como la Ford», con la renovación organizativa de 1912. A continuación el diseño encontraría un momento decisivo de perfeccionamiento con la transferencia del centro más importante de producción de Lingotto a Mirafiori en el período de entreguerras, que se habría de repetir en la disposición organizativa que siguió a la Segunda Guerra Mundial, es decir, en el momento que ahora estamos considerando.

La producción masiva, según el modelo de la Ford, hizo necesarios mecanismos organizativos de regulación en una forma de tendencia muy pura. El principio de organización que incorpora es la posibilidad de previsión a través de la normalización. Organización jerárquico-funcional centralizada, división rígida entre el contexto de la decisión y el contexto de la ejecución, actividades ejecutivas simples que pueden ser rápidamente aprendidas y repetidas sin errores trazan el panorama del proyecto de eficiencia interna de un sistema de empresa en el cual la lógica de la producción está en el centro estratégico del proceso y el diseño del sistema de las máquinas está en el centro de la lógica de la producción. En el exterior, sólo condiciones aceptables de relativa estabilidad y previsibilidad de los mercados y del ambiente social permiten la estrategia del fuerte y rígido empleo de capital que persigue la producción de masa. Por otra parte, precisamente el crecimiento permite obtener recursos acumulativos de estabilización y eliminación de incertidumbre: el monopolio es el caso límite de un mercado organizado, y en la postguerra, durante muchos años, la Fiat tiene prácticamente el monopolio de la industria del automóvil en Italia.

$\mathrm{Al}$ fin de los procesos de eliminación de incertidumbre, tiene especial importancia -entre organización interna y mercados externos- el control del ambiente próximo, que, definido en función del mercado, comprende sobre todo el mercado del trabajo y el mercado de los abastecimientos. En la fase fordista que estamos considerando, estos dos mercados han sido, en realidad, sistemas de relaciones económicas fuertemente organizados. El gran crecimiento de la Fiat, que arrastró tras de sí a la economía turinesa, implica la búsqueda de un depósito externo de fuerza de trabajo, que extiende los confines de Turín. y activa el proceso inmigratorio. El mercado toma la forma de un monopsonio, caracterizado por una demanda concentrada y por una oferta muy fragmentada. Aquí no interesa tanto conseguir las ventajas comparativas que esta configuración permite en función del costo de trabajo y de la elasticidad de su uso. Merece la pena subrayar la independencia y la capacidad de control sobre las variables de costo y de cantidad, y, por con-

4 Ibid., p. 196. 
siguiente, la absoluta previsibilidad a priori, que la existencia de la divergencia económica norte-sur y la vigorosa oferta de trabajo a que da lugar permiten por un período de tiempo prolongado. Así, pues, podemos hablar de un mercado, pero como caso límite de un mercado cuyas condiciones están fuertemente controladas; en nuestro lenguaje se trata, también y sobre todo, de un caso límite de organización. Una vez insertos en la fábrica, criterios de antigüedad, de adhesión a los valores empresariales, de capacidad y competencia seleccionan trayectorias de carrera, en relación con las cuales, a veces, los economistas usan la expresión «mercados internos del trabajo», pero que en realidad son reguladas por procesos de planificación organizativa.

En cuanto al sistema de los proveedores no disponemos de investigaciones analíticas de economía industrial, sino de descripciones que, sin embargo, proporcionan una imagen bastante precisa. Es necesario distinguir entre la función de abastecimiento en sentido estricto y las posibles relaciones con empresas menores «originadas por razones técnicas de apoyo, defensa, asistencia a los aprovisionamientos, producciones, finanzas» ${ }^{5}$. En ambos casos, las relaciones de mercado resultan marcadamente organizadas. Nos encontramos con dos posibilidades: o bien formas de participación en la empresa menor, que a menudo implican un estricto control de la tecnología y de los precios de cesión, ejercido muchas veces por hombres provenientes de la casa matriz; o bien, en el caso del inducido propiamente dicho, relaciones no formalizadas de participaciones en la propiedad, pero marcadamente influidas por las condiciones de monopsonio y de relaciones particulares. La promoción de un amplio círculo de empresas proveedoras y subcontratistas a comienzos de la década de 1950 se ha descrito así: "De esto da testimonio la constitución de un ente (la Unione Finanziamenti Industriali), encargado tanto de proporcionar anticipos, previo interés a cuenta sobre el saldo de los pedidos, como de la concesión de préstamos particulares para la adquisición de materiales y maquinarias. De esta manera, un grupo cada vez más numeroso de pequeñísimas empresas metalúrgicas, que no contaba con reservas adecuadas y obligadas a vivir a costa de un rápido giro financiero, empezaron a depender de la Fiat y a trabajar, sobre pedidos puntuales y a precios preestablecidos, en la fabricación de partes independientes o de piezas en serie» ${ }^{6}$. La organización fordista de la empresa y el control organizativo y de monopsonio del medio próximo constituyeron la base de un rápido crecimiento que contribuyó a impulsar a la economía turinesa y nacional por el camino de crecimiento de las grandes economías contemporáneas, a la par que imprimían una dirección bien determinada a la forma de desarrollo de la sociedad urbana.

${ }^{5}$ A. Mosconi y E. Rullani, Il gruppo nello sviluppo dell'impresa industriale, con un'analisi del caso Fiat, Milán, 1978.

- V. Castronovo, Imprese ed economia in Piemonte dalla "grande crisi» ad oggi, Turín, 1977 , p. 82. 


\section{La nueva fase: la economía entre organización y mercado}

A lo largo de la década de 1960 se manifiestan importantes tensiones generalizadas en las grandes economías. Al mismo tiempo, pierden eficacia las grandes unidades de producción fordista y las políticas económicas keynesianas que, durante un largo período, habían permitido estabilizar la economía hacia la plena ocupación. La organización de la empresa fordista, con su propio crecimiento, pretendía disminuir las posibles situaciones de incertidumbre en el medio circundante, especialmente en sus mercados. Sin embargo, la complejidad y la incertidumbre de las condiciones que se impusieron fueron de tal magnitud que los esquemas organizativos tradicionales no pudieron reducirlas. La gran empresa se enfrentó a desafíos culturales relacionados con nuevas actitudes en relación con el trabajo y con los consumos; a desafíos politicos, relacionados con la fuerza adquirida por los intereses organizados y por la dificultad de los acuerdos; a desafíos tecnológicos, como consecuencia de la rapidez y profundidad de los procesos innovadores y de las nuevas alternativas que se abren para la organización del trabajo; a desafíos de mercado, relacionados con el surgimiento de diferenciaciones más marcadas y con la presencia de empresas internacionales. En la nueva era de la incertidumbre, los mecanismos organizativos de una fase menos compleja pierden eficacia. En la economía se busca «elasticidad», y la palabra genérica oculta un profundo cambio en los modelos de acción que surgen en la sociedad moderna: el desplazamiento relativo de la racionalidad sinóptica a la racionalidad procesual ${ }^{7}$.

Sinóptica es la pretensión de una orientación global y ambiciosa, capaz de determinar la definición de los fines y de los medios a priori. Una racionalidad de este tipo se hace posible, desde el punto de vista teórico, cuando se dispone de todas las informaciones, cuando los objetivos son estables y sin ambigüedades, si los sistemas de valoración de los actores y de los intereses son absolutamente los mismos. Un contexto simple y relativamente estable, o un cambio orientado por esquemas fácilmente previsibles, hacen posible la racionalidad sinóptica. Pero cuando nos alejamos a ojos vistas de condiciones de este tipo surgen orientaciones de racionalidad definidas por procesos interactivos, en los cuales fines y medios se redefinen por ajustes sucesivos, con acuerdos parciales, esquemas pragmáticos y descentralización de las decisiones, donde elementos de organización estadística a posteriori pueden presentarse como un recurso de ajuste. En síntesis, el modelo interactivo, al contrario del sinóptico, tiene un carácter experimental que permite «de paso» hallar nuevos recursos y vías de solución a través de la interacción social. Evidentemente, la dicotomía sinóptico-procesual sólo indica dos polos extremos. Es preciso

${ }^{7}$ Sobre el uso de estas categorías en las ciencias sociales, véase, a modo de ejemplo, C. Lindblom, Politica e mercato. I sistemi politico-economici mondiali, Milán, 1979. 
decir una vez más que los sistemas concretos de acción se consolidan en soluciones intermedias. Por lo que respecta a la industria, el desarrollo de sistemas localizados de pequeñas empresas constituye un buen ejemplo de las posibilidades que se abren, en las nuevas condiciones, a la lógica de la racionalidad procesual y a los esquemas interactivos, por determinados tipos de producción. Esta forma de reacción a la crisis anticipa una tendencia más generalizada que también adopta la gran industria.

En las nuevas condiciones, el mercado se configura como el sistema más simple que permite ajustes simplificados a posteriori, y de hecho asistimos por doquier al retorno de elementos de mercado en la regulación de las relaciones económicas. Sin embargo, al principio, el uso del mercado es rudimentario: la descentralización de la actividad productiva, tanto en Italia como en otros países, en Piamonte como en el resto del país, es un esquema regulador que recurre al mercado para obtener sólo bajos costes de trabajo y elasticidad en su uso, en condiciones modificadas. Esta idea no conduce, por sí misma, a ningún cambio de los esquemas reguladores. Sólo a través de un proceso de aprendizaje puede aparecer el mercado como un esquema útil para procesos interactivos experimentales, como componente de formas organizadoras más complejas y estabilizadas de las relaciones económicas, entre actores diferenciados y autónomos. La distinción es importante para comprender los elementos de novedad que emergen de la crisis y para considerar, en particular, las condiciones en las cuales el mercado puede formar parte de esquemas reguladoras de la división por especialidades del trabajo entre empresas. Como quiera que sea, asistimos por doquier a la recuperación de importancia de elementos de mercado en la regulación de la economía, con significados diversos y mutables en el tiempo. Por lo que respecta a Turín, podemos decir también que, por primera vez, la sociedad local vuelve a medir sus límites y posibilidades frente al mercado.

En la reorganización interna de la Fiat hacen su aparición, sobre todo, los elementos de mercado. Tras una primera transformación de la rígida estructura jerárquica con la introducción de esquemas divisorios en 1970, en 1976 se constituyó un bolding que, al fin del proceso de reorganización, resultará subdividido en 11 sectores, con distintas sociedades operativas. De esto se deriva una descentralización de las decisiones, una exposición más directa de las unidades descentralizadas a la verificación del mercado exterior y relaciones de competencia entre los subbolding en relación con las respectivas rentabilidades. Se puede discutir sobre las dificultades con que tropieza el proceso y sobre las disfunciones de la nueva disposición; de todos modos, hay que decir que la nueva configuración trae aparejada una organización flexible de la empresa, en la cual el desplazamiento sinóptico del modelo fordista no conseguía 
ya hacer frente a las disfunciones burocráticas internas, y todavía menos la adaptación a un ambiente mutable y cada vez más complejo ${ }^{8}$.

L̊as innovaciones en cuanto a organización se producen al mismo tiempo que una rápida mutación tecnológica interna. La busca de flexibilidad en los mercados, orientados a reducir al mínimo las reservas y las existencias de productos acabados, trajo aparejadas innovaciones, tanto técnicas como organizativas, en las fábricas y en las oficinas; entre los ejemplos más notables de ello figuran la introducción de los robotgate para la soldadura, las líneas asíncronas de montaje de motores (Lam), los sistemas de diseño informatizado (Cad). Al mismo tiempo, se manifiestan también efectos inducidos en la trama de los proveedores y en el conjunto de los productores de componentes del automóvil. La investigación a la cual ya hemos hecho referencia traza un panorama diferente, en muchos aspectos, del que se ha descrito para la fase precedente $^{9}$.

Las empresas seleccionadas —aproximadamente, 300-, con más de 60.000 asalariados, están localizadas casi todas en la provincia de Turín e identifican a un sistema regional en el cual la proximidad física permite rápidas interacciones. El conjunto se caracteriza por una notable diferenciación interna en cuanto a la forma de propiedad, a la tecnología adoptada, a los tipos de producción y de elaboración y al grado de autonomía. El mismo constituye un sistema en el cual la organización, por medio de la presencia de asociadas de Fiat y de grupos exteriores y locales y de la influencia directa sobre los trabajos menores, se combina con relaciones de mercado menos desequilibradas en el interior y con la salida hacia mercados exteriores. Aunque es indudable que la Fiat tiene un firme control del medio, también es probable que la mezcla de organización y mercado permita en muchos casos una división especializada del trabajo entre las empresas que permite obtener efectos de sistema como consecuencia de procesos interactivos entre las unidades capaces de proyección y propuesta, con eficacia comprobada por el propio mercado. Por lo que respecta a la autonomía, merece la pena señalar una conclusión de una investigación según la cual, «tanto en lo referente a la facturación total como a la del sector automóvil, la dependencia de la Fiat Auto es indudablemente inferior a las expectativas y a las descripciones corrientes». El siguiente podría ser un panorama realista: las pequeñas empresas de elaboración parecen mantener una fuerte dependencia respecto de la Fiat; las empresas más grandes que corresponden a aprovisionamientos de primera implantación, bien equipadas en cuanto a tecnología, establecen relaciones interactivas con el comprador principal; un grupo significativo de empresas menores está orientado hacia el exterior del ciclo Fiat, a menudo a los mercados

${ }^{8}$ Un análisis del cambio de organización de la Fiat es el que realiza V. Comiro, $L a$ Fiat tra crisi e ristrutturazione, Roma, 1982.

9 ENRIETTI y Follis, «Il settore dei componenti...», cit. 
de recambios, poniendo en práctica políticas innovadoras para hacer frente a una fuerte competencia.

Atraer la atención sobre la Fiat de una manera excesiva, y, en consecuencia, simplemente sobre el sistema de sus proveedores, oculta el hecho de que esto constituye sólo una parte de lo que puede considerarse, en conjunto, la segunda gran industria turinesa: la industria de los accesorios, definida no por un sector de mercancías en particular, sino por la tipología del mercado, característica de los ambientes industriales de elevado desarrollo. Consideramos que observar de cerca esta compleja realidad es importantísimo porque permite sacar a la luz precisamente los cambios del juego de mercado y de la organización. Una investigación sobre la industria de los accesorios del área turinesa ${ }^{10}$, que se realizó en 1980 y que no incluye a los artesanos, ha contabilizado un número de 1.115 empresas que actúan en los mercados intermedios y de los bienes de inversión, con una ocupación de más de 121.000 asalariados. Entre los sectores que abarca figuran la mecánica, la electromecánica, las industrias del plástico y del caucho, la electrónica, los servicios, las industrias de aparatos y matrices, de máquinas e instalaciones. Aproximadamente, una cuarta parte de las empresas producen bienes de inversión, la gran mayoría productos y elaboraciones que entran en el producto final. Las empresas con más de 1.000 asalariados absorben un tercio de la ocupación; las pequeñas, con un máximo de 100 asalariados, sólo una cuarta parte. Nos encontramos ante una realidad palpable a la que no siempre se le da la importancia que merece. La industria en cuestión no es nueva - una cuarta parte tiene un origen anterior a la guerra-, aunque en los últimos años ha experimentado un proceso de consolidación y de importante recualificación técnico-productiva. Entre los mercados principales encontramos, una vez más, el del automóvil, pero junto a varias otras industrias. Nos encontramos con sistemas de empresas localizadas, con un auténtico distrito industrial, como lo demuestra el hecho de que más de la mitad de las empresas tiene en la región su propia salida de mercado principal y de que los proveedores recurren, a su vez, a subcontratistas para un volumen del 28 por 100 de sus compras globales, que realizan en su mayor parte dentro de la provincia.

Nuestro problema consiste en tratar de determinar si el régimen de los sistemas de aprovisionamiento y subcontratación puede definirse simplemente como un control ejercido por el mercado, en el cual se encuentran estructuras de marcada dependencia, o bien como un uso interactivo del mercado, con posiciones más autónomas y con perspectivas de desarrollo de formas acordadas de estabilización de las relaciones de los sistemas de empresas, mediante formas organizativas apropiadas. Los datos sobre los tipos de relaciones entre

10 Agenzia Industriale Italiana, Potenzialità di sviluppo dei mercati di fornitura nell'area torinese, Turín, 1981. 
empresas, sobre las aportaciones de planificación, sobre los factores de competitividad, sobre el poder contractual y sobre otros elementos llevan a la conclusión de que las empresas marcadamente dependientes constituyen una estrecha franja y de que se considera a la calidad y a la fiabilidad, más que a los precios, como factores decisivos de competitividad. Por otra parte, estos signos de un mercado de aprovisionamiento como regulador interactivo aparecen en compañía de otros que muestran la escasez de formas de organización de las relaciones entre empresas que estabilicen la simple relación de mercado: el 92 por 100 de los empresarios proveedores señala frecuentes dificultades de acuerdo con los comitentes, mientras que el 72 por 100 considera importante modificar la posición contractual de la empresa. Además, sólo el 13 por 100 de las empresas tiene con los principales comitentes contratos marco que aseguren y codifiquen, con garantías recíprocas, las relaciones entre las partes por períodos anuales o plurianuales. Las empresas de mayores dimensiones tienen un número restringidísimo de clientes, y el mismo está vinculado a la participación en grupos de diversa composición y, por lo tanto, a una regulación más directamente organizativa de las relaciones. Un número restringido de clientes es también característica de las empresas más pequeñas, reguladas por relaciones de monopsonio. Entre ambas se va abriendo camino, aunque no sin dificultades, que todo hay que decirlo, la regulación interactiva entre mercado y organización.

La crisis de la gran industria acaecida a fines de la década de 1970 ha vuelto a ampliar el espacio de la pequeña empresa; para algunos sectores y en algunas regiones, esto ha significado una auténtica movilización del mercado desde la base. Incluso en el área turinesa se observan signos evidentes de la reactivación de la pequeña industria. Durante esa década, las clases de pequeñas empresas adquiere mayor peso, y esto no como consecuencia de una caída menor de la ocupación con respecto a las grandes, en retroceso, sino al aumento en las clases de hasta 50 asalariados.

Una investigación reciente " ha mostrado el aumento relativo de la capacidad para crear nuevas empresas industriales, pequeñas y medianas, en el contexto turinés frente al milanés en el período más reciente. Una comparación entre 1981 y los años más próximos permite ver que la proporción de nuevas empresas de tecnología avanzada tiende a aumentar, también en este caso, al contrario de lo que sucede en Milán. Otra investigación ha señalado la notable capacidad de las empresas localizadas en el área turinesa para producir patentes ${ }^{12}$. De acuerdo con estos indicios, deberemos prestar atención a los recursos ambientales específicos, constituidos por las elevadas capacidades de planificación y de aplicaciones técnicas, incluso con respecto a las nuevas formas

1 E. Ciciotri y A. Monteverdi, Rapporto sulla natalità industriale nella provincia di Torino (1980-1982), en ciclostil, Fundación G. Agnelli, 1986.

${ }_{12}$ C. ANTonell, L'attività innovativa in un distretto tecnologico, en ciclostil, Fundación G. Agnelli, 1986. 
de iniciativa empresarial difusa. Se trata de una realidad en movimiento de cuya evolución pueden depender cambios importantes para la organización social de la producción en Turín y para la diferenciación de la economía local, En un futuro próximo deberá centrarse sobre ella la atención ${ }^{13}$.

Con respecto a lo dicho hasta ahora, no nos parece, pues, que el término desindustrialización sea el más adecuado para definir la situación de la economía turinesa. No lo es si por él se entiende simplemente crisis de la industria, pero tampoco lo es si se entiende pérdida importante del peso de la industria en el conjunto de la economía. Incluso el proceso de terciarización, cuya presencia es innegable, confirma este panorama si se lo observa con atención. No se trata sólo de que este proceso esté ahora relativamente limitado si se compara, por ejemplo, con Milán, sino que también debe tenerse en cuenta que las actividades en las cuales Turín tiende a especializarse son los servicios vinculados más directamente a la producción y a la organización y no los servicios financieros, de publicidad, de mercado. En suma, se confirma la imagen de Turín como metrópoli industrial.

\section{Tendencias de la estructura social}

Las particularidades del crecimiento industrial turinés han influido de manera muy marcada en el proceso global de desarrollo de la sociedad metropolitana. Esta se ha estructurado de acuerdo con la capacidad de inclusión de recursos humanos y materiales de que era capaz la gran industria con su proyecto de innovación económica y social.

El proceso de inclusión puede observarse tomando como base las características de la estructura socioprofesional de la población. Hemos visto ya la importancia fundamental de la industria en la formación social metropolitana, que sólo se redefinió en los últimos tiempos. El censo de la población indica que en la provincia, en el año 1961, trabajaba en la industria el 61 por 100 de la población activa; en 1971 , el 62,3 por 100 ; en 1981 , el 51,5 por 100 . Como vemos en esta serie, 1971 señala el punto máximo, que podemos considerar el punto de partida hacia nuevas situaciones que debemos evaluar.

En el siguiente cuadro puede verse la estratificación social de la industria:

${ }^{13}$ Un análisis preliminar del surgimiento de un sistema de pequeña empresa de especialización flexible y de alta tecnología en el área de Turín puede encontrarse en A. Michelsons, Turin between Fordism and Flexible Specialization, tesis de doctorado, Cambridge (R. U.). 


\begin{tabular}{|c|c|c|c|}
\hline & 1961 & 1971 & 1981 \\
\hline 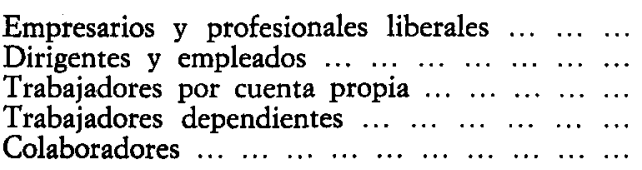 & $\begin{array}{r}0,8 \\
12,9 \\
5,2 \\
80,1 \\
0,9\end{array}$ & $\begin{array}{r}1,0 \\
17,9 \\
5,8 \\
74,5 \\
0,7\end{array}$ & $\begin{array}{r}1,0 \\
22,3 \\
6,4 \\
69,5 \\
0,8\end{array}$ \\
\hline & $(491.481)$ & $(557.051)$ & (494.808) \\
\hline
\end{tabular}

En general, las tendencias en el tiempo son similares a las que se manifiestan en todos los países industrializados. En particular, se observa la disminución de la repercusión de los obreros y el aumento de los empleados y dirigentes. Las cifras absolutas indican, además, el punto máximo de preponderancia de la industria en 1971, pero desplazan hacia 1961 la evidencia de un carácter específico de la estratificación, más típico de la primera fase: la neta polarización entre una franja muy restringida de burguesía empresarial y una gran masa obrera. A continuación, la polarización tenderá a disminuir por la aparición de las categorías que «están en el medio».

Con otros datos podemos precisar mejor las características de esta población. El cuadro siguiente muestra la distribución de los trabajadores de las industrias de transformación de acuerdo con las dimensiones de las empresas:

\begin{tabular}{|c|c|c|c|}
\hline & 1961 & 1971 & 1981 \\
\hline 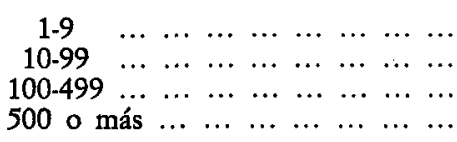 & $\begin{array}{l}12,7 \\
20,9 \\
20,5 \\
45,9\end{array}$ & $\begin{array}{r}9,5 \\
18,2 \\
17,9 \\
54,4\end{array}$ & $\begin{array}{l}12,3 \\
22,2 \\
19,6 \\
45,9\end{array}$ \\
\hline 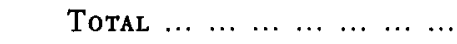 & 100 & 100 & 100 \\
\hline
\end{tabular}

Los datos nos indican que los asalariados, en particular los obreros, están concentrados casi en un 50 por 100 en grandes unidades (de 500 asalariados o más), y que el máximo de concentración se observa en 1971, correspondiéndose con el comienzo, apenas esbozado, de una menor polarización. Esto significa que a lo largo de toda la década de 1960 está presente un elemento de homogeneización de la clase obrera debida a la condición de grandes fábricas compartidas por muchos obreros. Pero significa también que una menor polarización registrada en el panorama anterior a 1971 se ve compensada por este aumento de la concentración. Como consecuencia de ello permanece inalterada 
a lo largo de la década de 1960 la fuerte y peculiar estructuración de la clase obrera.

La tabla que a continuación se incluye se refiere al porcentaje de obreros no especializados y permite considerar además las tendencias de polarización y de homogeneidad interna de la clase obrera, el proceso de descualificación $\mathrm{y}$, por consiguiente, de posibilidad de intercambio de los trabajadores que puede ser un elemento importante dentro del proceso de proletarización. La. tabla es compleja, por cuanto debe incorporar fuentes diversas, y sólo puede señalar las tendencias generales. Con todo, permite demostrar que el porcentaje de obreros no especializados aumentó de una manera neta entre 1951 y 1967 , volviendo a disminuir a continuación; también permite observar que la industria del automóvil - y en particular la industria turinesa del automóviltiene unos efectos de descualificación mayores que el resto de la industria.

Asimismo, se confirma que durante la década de 1960 se suman condiciones de polarización, homogeneización y proletarización muy marcadas. En consecuencia, dicha década puede considerarse como el momento máximo de organización fordista de la industria e hipotéticamente, por lo tanto, el momento de máximo impacto de la formación social estructurada sobre esta base en el conjunto de la sociedad local. Con la expresión formación social se indica la congruencia relativa que tiende a establecerse entre las formas de organización de la economía y otros niveles de estructura social, en particular la política y la cultura.

\begin{tabular}{|c|c|c|c|c|}
\hline & 1951 & 1961 & 1967 & 1979 \\
\hline \multicolumn{5}{|l|}{ Obreros industria automóvil } \\
\hline $\begin{array}{lllllllllll}\text { Italia } & \ldots & \ldots & \ldots & \ldots & \ldots & \ldots & \ldots & \ldots & \ldots & \ldots \\
\text { Fiat } & \ldots & \ldots & \ldots & \ldots & \ldots & \ldots & \ldots & \ldots & \ldots & \ldots \\
\text { Turín } & \ldots & \ldots & \ldots & \ldots & \ldots & \ldots & \ldots & \ldots & \ldots & \ldots \\
\text { Milán } & \ldots & \ldots & \ldots & \ldots & \ldots & \ldots & \ldots & \ldots & \ldots & \ldots\end{array}$ & $\begin{array}{l}39,1 \\
35,2 \\
-\end{array}$ & $\begin{array}{l}46,4 \\
47,9 \\
- \\
-\end{array}$ & $\begin{array}{l}66,3 \\
\overline{66,3} \\
44,0\end{array}$ & $\overline{-}-$ \\
\hline \multicolumn{5}{|l|}{ Obreros industria general } \\
\hline $\begin{array}{ccccccccccc}\text { Turín } & \ldots & \ldots & \ldots & \ldots & \ldots & \ldots & \ldots & \ldots & \ldots & \ldots \\
\text { Milán } & \ldots & \ldots & \ldots & \ldots & \ldots & \ldots & \ldots & \ldots & \ldots & \ldots\end{array}$ & - & - & $\begin{array}{l}50,2 \\
38,5\end{array}$ & $\underline{34,3}$ \\
\hline
\end{tabular}

A continuación echaremos una mirada a la sociedad en su conjunto valiéndonos para ello del cuadro siguiente, que se refiere a la estructura profesional de la población activa de la provincia en los tres censos. 


\begin{tabular}{|c|c|c|c|}
\hline & 1961 & 1971 & 1981 \\
\hline 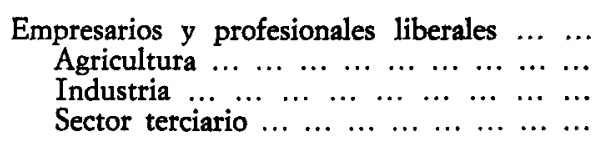 & $\begin{array}{l}0,01 \\
0,5 \\
0,8\end{array}$ & $\begin{array}{l}0,02 \\
0,6 \\
1,1\end{array}$ & $\begin{array}{l}0,13 \\
0,5 \\
2,6\end{array}$ \\
\hline 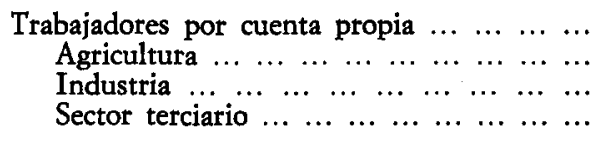 & $\begin{array}{l}5,5 \\
3,2 \\
6,3\end{array}$ & $\begin{array}{l}3,4 \\
3,6 \\
6,5\end{array}$ & $\begin{array}{l}2,5 \\
3,3 \\
7,3\end{array}$ \\
\hline $\begin{array}{rlllllllll}\text { Colaboradores } & \ldots & \ldots & \ldots & \ldots & \ldots & \ldots & \ldots & \ldots & \ldots \\
\text { Agricultura } & \ldots & \ldots & \ldots & \ldots & \ldots & \ldots & \ldots & \ldots & \ldots \\
\text { Industria } & \ldots & \ldots & \ldots & \ldots & \ldots & \ldots & \ldots & \ldots & \ldots \\
\text { Sector terciario } & \ldots & \ldots & \ldots & \ldots & \ldots & \ldots & \ldots & \ldots\end{array}$ & $\begin{array}{l}3,8 \\
0,6 \\
1,8\end{array}$ & $\begin{array}{l}1,1 \\
0,5 \\
2,1\end{array}$ & $\begin{array}{l}0,6 \\
0,4 \\
2,1\end{array}$ \\
\hline 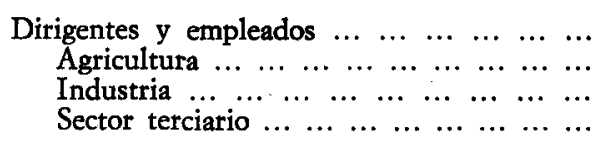 & $\begin{array}{l}0,04 \\
7,9 \\
8,6\end{array}$ & $\begin{array}{cc}23,7 & \\
0,04 \\
11,2 \\
12,4\end{array}$ & $\begin{array}{r}29,9 \\
0,07 \\
11,5 \\
18,3\end{array}$ \\
\hline 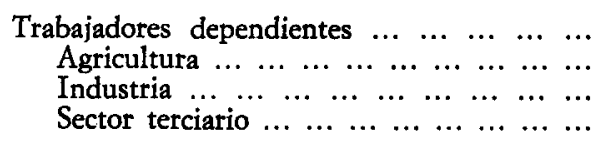 & $\begin{array}{r}60,9 \\
0,7 \\
48,9 \\
11,2\end{array}$ & $\begin{array}{r}57,3 \\
0,3 \\
46,4 \\
10,6\end{array}$ & $\begin{array}{r}50,6 \\
0,6 \\
35,8 \\
14,2\end{array}$ \\
\hline $\begin{array}{lllllllll}\text { Total activos } & \ldots & \ldots & \ldots & \ldots & \ldots & \ldots\end{array}$ & $\begin{array}{l}100 \\
(804.220)\end{array}$ & $\begin{array}{l}100 \\
(893.354)\end{array}$ & $\begin{array}{l}100 \\
(960.679)\end{array}$ \\
\hline
\end{tabular}

$\mathrm{Si}$ incluimos los caracteres sociales de la industria en el panorama más amplio de la sociedad local, se mantiene la imagen de una sociedad simple: una neta dicotomía burguesía-proletariado con pocos elementos en medio. Las cifras de 26.000 trabajadores por cuenta propia en la industria y 50.000 en el sector terciario representan cantidades importantes para 1961, pero indican, sin embargo, que la antigua clase media independiente sólo representaba el 15 por 100 del total, siendo apenas mayor el peso de las nuevas clases medias empleadas. Observemos las tendencias en el tiempo: se confirma la reducción de los asalariados, pero surgen aspectos nuevos en lo que respecta a las clases medias. Mientras tanto, a pesar de la recia caída de los campesinos, la antigua clase media mantiene su espacio, y el mantenimiento de esta clase teóricamente en declinación es consecuencia de su expansión en el sector terciario. Es digno de tenerse en cuenta que el crecimiento de la burguesía empresarial debe atribuirse principalmente al desarrollo de pequeñas empresas $y$, en general, al crecimiento de una categoría atribuible a la antigua clase media independiente. También se observa un marcado aumento de empleados y dirigentes, pero no en la industria después de 1971, aunque sí en el sector terciario. Concluyendo, se puede afirmar que si transcurridos veinte años con- 
tamos con una estructura social relativamente más diversificada, esto debe atribuirse principalmente a la dinámica del sector terciario.

Los datos mencionados individualizan a la perfección el núcleo de estructuración de la formación social basada en la gran empresa fordista. Lo hacen mostrando las cifras típicas de esta estructuración, pero, según ya se ha dicho aquí, es preciso pensar que este núcleo opera en cierta medida sobre la estructuración de las mentalidades, de los modos de organización de los intereses, de los conflictos típicos; o sea, en general, de un mundo social específico.

Claro que la formación social de la gran industria no es el único principio de estructuración de la sociedad metropolitana turinesa. Perviven elementos de antiguas formaciones, otros son más específicos de lo que suele pensarse (la sociedad de la administración pública, por ejemplo), y también hay síntomas de un nuevo resurgimiento, por ejemplo, el mundo social de las pequeñas empresas de alta tecnología. Sin embargo, la importancia de la formación de grandes industrias es tan grande que en la actualidad tal vez debamos esperar que los elementos más importantes de transformación surjan de los movimientos de la mayor parte de la sociedad local involucrada en la formación de la gran industria.

Desde esta perspectiva, no cabe duda de que el hecho más significativo es la inversión del proceso de homogeneización de la fuerza de trabajo ${ }^{15}$ con una nivelación generalizada en las bajas cualificaciones. Podemos formarnos una idea de la vastedad y profundidad de las modificaciones en curso, tomando como ejemplo las consecuencias de la introducción del robotgate en la planta de chapistería de la Fiat en Rivalta. Los obreros directos, que eran el 70 por 100 del turno de 200 , aproximadamente, se redujeron al 10 por 100 , dejando espacio a indirectos de servicio en la producción, a obreros de mantenimiento y de servicios generales, por un total aproximado de 60 operarios. Con datos de referencia más generales se puede observar que en la planta de carrocerías de Rivalta, donde trabajan unos 9.000 obreros, la relación entre obreros especializados y no especializados ha pasado de 1 a 10 en 1976 a 1 a 5 en 1981. Es difícil predecir la importancia del proceso de recualificación en perspectiva, y aún más imaginar el significado que tendrá a largo plazo para la sociedad en su conjunto. Como quiera que sea, las tendencias de recualificación implican una mayor diferenciación interna en el seno de la clàse obrera, y esto se suma a las tendencias más generales de diferenciación descubiertas hasta ahora, definiendo en conjunto un cuadro social en movimiento. La nueva organización del trabajo requiere personal más profesiona-

14 En 1961, las clases dimensionales son: 1-10, 11-100, 101-500, 501 y ss.

15 Sobre estos procesos, véanse A. Becchi Collida y S. NEgrelli, La transizione nell'industria $e$ nelle relazioni industriali, Milán, 1986; C. CIBORRA y F. LANZARA (eds.), Progettazione delle nuove tecnologja e qualità del lavoro, Milán, 1984; A. ENRIETTI, «L'innovazione di processo in Fiat», en A. Michelsons (ed.), Tre incognite per lo sviluppo, Milán, 1985. 
lizado e interactivo, con movilidad y responsabilidad. El cuadro es muy similar para el sector empleados, donde los trabajos más reiterativos serán suprimidos por el desarrollo de la ofimática, con previsibles pérdidas de puestos de trabajo en los próximos años. El cambio de la organización del trabajo y, en consecuencia, el proceso de recualificación son también el resultado de los conflictos sociales de los últimos años. De manera similar, también las estructuraciones futuras dependerán de las dinámicas sociales que la nueva condición pretenda implantar. Pero si es difícil hacer previsiones sobre las consecuencias de dichas tendencias, en cambio resulta fácil predecir que de esas dinámicas dependerán elementos cruciales de las futuras estructuraciones de la sociedad turinesa.

\section{El conflicto de intereses: una consecuencia más de la organización}

Por lo general, una forma particular de organización social de la economía se asocia a formas particulares de cultura y a modalidades determinadas de la política, de la organización de los intereses y de la conflictividad. Nos hemos referido a esta congruencia de las tendencias con la expresión «formación social» (o, de una manera más coloquial, mundo social). Hemos dicho también que, por lo general, en una sociedad concreta coexisten varias formaciones sociales estructuradas en torno a principios diferentes, y hemos señalado algunos ejemplos de posibles formaciones coexistentes en Turín. No estamos en condiciones de desarrollar esta línea de investigación de una manera analítica. Podemos razonar, en cambio, sobre la naturaleza de la gran capacidad inclusiva de la formación fordista y sobre sus posibles evoluciones, lo cual permite, al menos, iniciar el discurso.

Intentaremos plantear la cuestión tomando como base la organización de los intereses y la forma de los conflictos que de ello surgen. Turín no sólo sirve de marco a los experimentos de las grandes organizaciones, sino también a los intentos de organización de la clase obrera. El hecho de que en Turín se tomase la decisión de «hacer como la Ford» significó una rápida revolución social. Con la concentración de una masa de obreros cada vez mayor, desarraigadas definitivamente de los contextos campesinos tradicionales, homogeneizada por las condiciones de las fábricas y, cada vez más, por la tecnología con tareas de baja cualificación, se crean las condiciones y las bases sociales para nuevas formas de conflictividad. Determinar la forma y el lugar en que nace este contrapoder, cuáles son los procesos de que se vale y en qué variantes se manifiesta constituye un complicado problema histórico. Desde un punto de vista sociológico, se puede señalar, haciendo abstracción de otras consideraciones, que la organización del movimiento obrero se encontró ante dos posibilidades que no se excluyen entre sí. Sin embargo, cuando se implanta una de las dos, puede constituirse una tradición organizativa y cultural que tiende 
a reemplazar a la otra. Según cuáles sean las oportunidades para el crecimiento de las organizaciones, el movimiento puede orientarse preferentemente o bien hacia el terreno político o bien hacia el de la fábrica. La orientación hacia el terreno político se ve favorecida por condiciones como la ampliación de los derechos de la ciudadanía y la posibilidad concreta de acceder al Gobierno; en cambio, favorecen la orientación hacia la fábrica las condiciones de trabajo imperantes en las grandes unidades de producción, que ofrecen la oportunidad de organizar acciones reivindicativas. El carácter limitado, y en el fondo excepcional, de la experiencia turinesa dentro del contexto nacional, sumado a las condiciones definidas por las grandes fábricas, hacen que el movimiento se oriente precisamente hacia la fábrica - la tradición obrerista- en lugar de hacerlo hacia el campo político.

Se nos plantea aquí otro complejo problema histórico cuando pretendemos determinar las causas de las orientaciones específicas y de los contenidos concretos que asume el movimiento, y que, en nuestro caso, son de orientación radical y maximalista ${ }^{16}$. Sin embargo, adoptando una vez más el punto de vista sociológico - en lo que respecta a la estructura de la situación- podemos suponer también en este caso que influyen los efectos directos de la gran organización. La oposición que surge no se expresa en contra del modelo industrial como tal. Más bien coloca a la industria en el centro de la acción política, definiendo la dinámica social como una dialéctica entre desarrollo de las fuerzas productivas y relaciones de producción: la clase obrera, constituida por la industria, es el sujeto capaz de hacerse cargo de la gestión de los medios de producción como consecuencia de un proceso histórico. Por este camino, la racionalidad sinóptica a prióri y totalizadora de la gran industria exige la aparición de una racionalidad que, como reflejo de aquélla, sea sinóptica y totalizadora. La cultura sindical del movimiento estará muy orientada por la ideología y muy radicalizada. De distintas maneras, y con un carácter más o menos marcado, esta orientación se mantendrá a través del tiempo. El desarrollo organizativo de la gran fábrica, y sus formas de conflicto con el movimiento, reproducen y refuerzan estas tendencias.

En esta situación, a la acción patronal se le presentan también dos caminos que no se excluyen mutuamente: la inclusión de alguna forma de representación de los intereses obreros en el interior mismo de su ámbito organizativo, con la creación de programas asistenciales directos y apoyados por un sindicato favorable o la lucha contra la organización del movimiento, dentro

${ }^{16}$ Estas tendencias se manifiestan con el desarrollo del modelo fordista. A comienzos de siglo, en la fase de arranque de la industrialización - sobre la cual haremos sucesivamente algunas referencias-, la organización de los intereses y las formas del conflicto comenzaban a estructurarse en diferentes modalidades. A este respecto, véanse C. BAGLIONI, L'ideologia della borgbesia industriale nell'Italia liberale, Turín, 1974, y G. CARoccI, Giolitti e l'età giolittiana, Turín, 1961, 1982. Sobre la fase más reciente de las relaciones industriales en Turín, véase M. GoLDEN, Austerity and its Opposition: Communism, Corporatism and Italian Labor Movement, de próxima publicación. 
y fuera de la fábrica. Es la historia de los «años duros de la Fiat», durante la fase de la construcción a gran escala del modelo fordista.

Si observamos a lo largo de un período prolongado un indicador normal de conflictividad sindical veremos que, al igual que otros indicadores precedentes, está sujeto a cambios cíclicos muy marcados. Veamos el gráfico que se refiere a la media anual de horas/obrero perdidas por huelga:

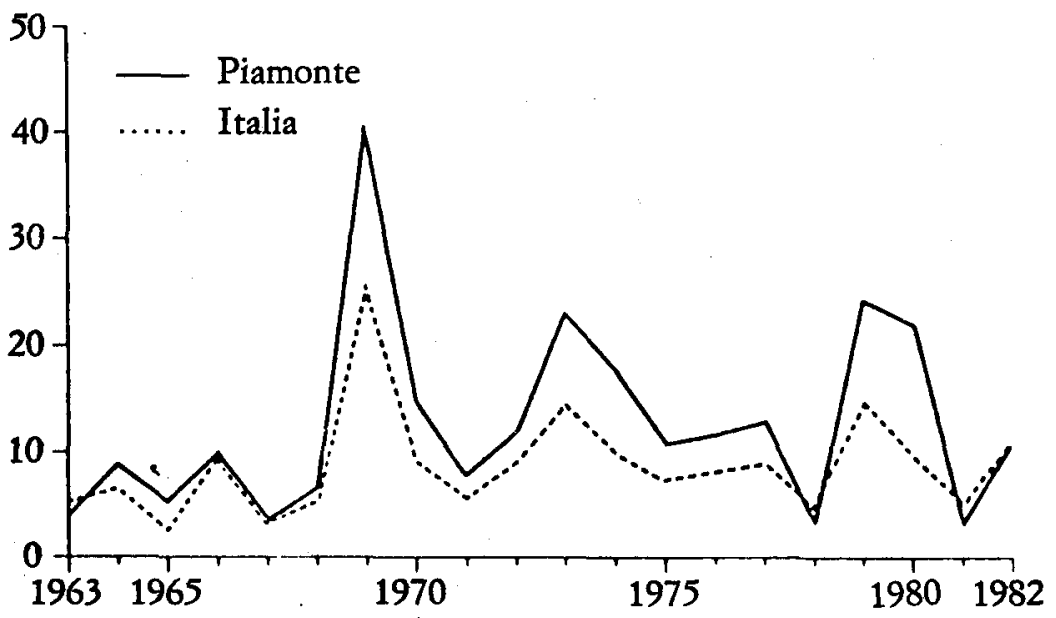

Merece especial atención el punto elevado del «otoño caliente», ya que indica el punto de máxima conflictividad laboral en el momento máximo de organización fordista de la industria. Después de ese momento, la conflictividad decae, pero también se redefine la organización; como consecuencia de ello, la totalidad del mundo social de la gran organización no volverá a ser la misma. Ese es el último momento en el que se puede concebir, de acuerdo con la tradición del movimiento turinés, la posibilidad de hacer política directamente con la acción sindical y a partir de la fábrica. Y, de hecho, en aquellos años se hizo una política sui generis, con la constitución del sindicato como sujeto representante de intereses generalizados, en un momento en que las instituciones propiamente políticas estaban en un atolladero que no les permitía tomar decisiones. La adecuación de los salarios a los del resto de Euro$\mathrm{pa}$, una legislación más moderna de la fábrica, cuestiones relacionadas con la vivienda, con los transportes, el subdesarrollo del Mediodía, representan grandes retos para una sociedad en vías de desarrollo, en cuyo seno existen grandes bolsas de parasitismo e ineficacia y un sistema político incapaz de garantizar alternativas reales de gobierno y vías de modernización. La anoma- 
lía de la situación salta a la vista. Por otra parte, la poca fuerza política del nuevo sujeto pronto se pone de manifiesto con la aparición de una fuerte inflación ocasionada por una fallida jerarquización de las demandas políticas de antiguo y de nuevo cuño, admitida, por otra parte, en función del control social. La descentralización de la actividad productiva hacia pequeñas empresas no sindicalizadas hizo el resto.

El intento realizado en el ámbito nacional de impulsar la situación hacia un nuevo sistema de relaciones industriales de carácter negociador no tuvo éxito o sólo lo tuvo en parte. Las mayores resistencias se encontraron precisamente en Turín. Un observador externo, con un conocimiento imperfecto de la realidad turinesa e italiana, podría haber sacado la impresión contraria, es decir, la de una aceptación más fácil en Turín. En realidad, en Turín existe la condición básica más importante para la estabilización de un sistema de relaciones industriales de tipo neocorporativista, caracterizadas por grandes acuerdos-marco sobre las orientaciones de fondo de la economía y de la política social, negociados por representantes de los sindicatos de los trabajadores y por los empresarios fuertes y reconocidos, capaces de garantizar el respeto a los pactos establecidos y recíprocamente legitimados, con el concurso de la acción mediadora y compensadora del Gobierno. La condición básica a la que nos referimos es la concentración industrial y la homogeneidad de los intereses en juego. Sólo un examen más minucioso permite descubrir que juegan desfavorablemente algunas condiciones particulares de Italia y de Turín. Ante todo, la excepción turinesa: ¿es posible concebir un sistema estable de decisiones triangulares con sus vértices en las grandes variables de la economía cuando la condición básica para ello - una marcada homogeneidad de los intereses representados - prácticamente se da sólo en una región del país (por no decir en un área metropolitana)? Por otra parte, ¿cómo es posible imaginar un sistema de ese tipo sólo a escala regional, cuando el alcance de los problemas y de los acuerdos en juego es nacional en muchos casos? Así, pues, está claro que falta una segunda condición, no menos importante, en relación con el caso italiano: la de un partido que represente con propiedad los intereses de la clase obrera, al cual se le ha negado sistemáticamente el acceso al Gobierno. Por lo que a Turín se refiere, en cuanto a la especificidad del movimiento y de su organización, tiene más peso la tradición cultural y organizativa de organización no negociadora. A su vez, esto pone en peligro, tanto en el ámbito local como en el regional, otra condición básica: la plena legitimación recíproca de los representantes.

En suma, el intento de un sistema de relaciones industriales capaces de hacer frente al gobierno de la economía y de vincular en puntos esenciales la economía y la política mediante-un típico mecanismo neocorporativista, llegó demasiado tarde y en condiciones bastante anómalas, cuando ya en otros países, aunque por motivos ligados a ulteriores transformaciones de la sociedad, se consideraba una disposición institucional con menor capacidad de orienta- 
ción y regulación. Si nos limitamos a hablar de «retraso», correremos el riesgo de subestimar la manera propia que tiene cada sociedad local o nacional para dar con su propia estructuración institucional. Sin embargo, en este caso, y al menos hasta cierto punto, la noción de retraso resulta útil. Las salidas institucionales de los grandes conflictos en los comienzos de la década de 1970 vienen, en cierto modo, a compensar un retraso. Suzanne Berger y Michael Piore lo han observado. Los derechos de autotutela sancionados por el Estatuto de los Trabajadores, especialmente en las fábricas, para una amplísima gama de problemas relacionados con la producción y con el trabajo, cubren un vacío de décadas con respecto a otros países.

También se encuentran elementos de especificidad en la radicalidad de normas igualitarias y de protección, como la escala móvil, fruto de una fuerza inmediata que no podía haber comprobado su viabilidad en el tiempo. Sin embargo, también se puede hablar de retraso en otro sentido. La crisis de fines de la década de 1960 en Turín es una crisis de marcada polarización social, centrada en la industria. Desde este punto de vista, se corresponde con una coyuntura particular de las formaciones sociales de las grandes empresas que en general no volverá a repetirse. En la sociedad que está surgiendo, la producción se ha descentralizado y la estructura económica y social ha adquirido una gran diferenciación. Todos los análisis anteriores de los indicios en este sentido señalan, y no casualmente, un retraso de Turín en este aspecto. La descentralización productiva, la inflación y otros factores han marchado a la par de la dispersión progresiva de la organización de los intereses de los trabajadores y del redimensionamiento de los sindicatos. Pero considerando el proceso dentro de un marco general, también se observan signos del surgimiento de nuevos tipos de relaciones económicas y de intereses.

Las sociedades modernas no se vuelven más simples con el paso del tiempo; por el contrario, alcanzan un mayor grado de complejidad y de diferenciación. Los problemas críticos que se plantean no son ya de fuerte polarización estructural de los intereses, sino de exceso de diferenciación de los mismos. Precisamente por ello se hacen más complejas y diferenciadas las mezclas reguladoras; la organización y el mercado se compenetran de diferentes maneras en cada contexto y en cada momento, e incluso la reciprocidad recupera su espacio en ámbitos determinados, con significados ambivalentes sobre los procesos de modernización y para la estructura de intereses. Pero, sobre todo, si bien una crisis de exceso de polarización puede representarse como un cortocircuito que aplasta la política relacionada con el sindicato, las cuestiones de exceso de diferenciación sólo pueden afrontarse con el concurso directo de la política. De ser correcta esta conclusión, tal vez nos encontremos ante el problema más serio de cuantos se plantean actualmente para el futuro de Turín. La sociedad turinesa es demasiado simple por cuanto tiene una organización económica todavía demasiado uniforme, una estructura social que se va diferenciando sin que se hayan individualizado todavía con claridad nuevos actores 
bien estructurados, y también un sistema político demasiado frágil y poco emancipado de la sociedad civil.

\section{Los sujetos del pluralismo y el espacio de la política}

La sociedad turinesa es, indudablemente, un depósito extraordinario de recursos culturales y materiales que, sin embargo, no parece estar en condiciones de valorar plenamente. No tenemos aquí espacio suficiente para documentar como se merece esta afirmación, pero bastará con recordar el desaprovechamiento de recursos humanos que representa la desocupación; la tasa de desocupados sobre la población residente era, en 1985, de 5,3 (en Milán, de 3,58 , y, en Bolonia, de 3,37). Como es natural, se están produciendo cambios, y tal vez podría decirse que se trataba de una situación bloqueada que se está desbloqueando en ciertos aspectos. Esto es precisamente lo que permite ver hoy el vacío de la política.

El sistema político turinés puede definirse como un sistema de partidos en competencia. No existe el neto y continuo predominio de un partido relacionado con una subcultura radicada y hegemónica; la historia de la postguerra demuestra que no se da siquiera la situación particular del sistema político italiano en su conjunto, que se ha definido como «bipartidismo imperfecto», en la cual dos partidos polarizan el electorado, pero ninguno está plenamente legitimado para ejercer el Gobierno. El cuadro que transcribimos a continuación muestra la fuerza electoral de los dos partidos principales en porcentaje de votos provinciales en las elecciones para la Cámara de los Diputados:

\begin{tabular}{|c|c|c|c|c|c|}
\hline & 1968 & 1972 & 1976 & 1979 & 1981 \\
\hline 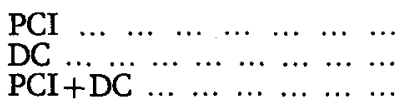 & $\begin{array}{l}29 \\
32 \\
61\end{array}$ & $\begin{array}{l}29 \\
33 \\
62\end{array}$ & $\begin{array}{l}39 \\
32 \\
71\end{array}$ & $\begin{array}{l}33 \\
30 \\
63\end{array}$ & $\begin{array}{l}33 \\
23 \\
56\end{array}$ \\
\hline
\end{tabular}

Como se ve, se trata, además, de un electorado bastante móvil; los datos muestran también que los dos partidos han llegado al valor máximo de polarización del electorado en 1976, mientras que a continuación se han ido abriendo espacios mayores para otros partidos. Los cambios no deben atribuirse sólo a la situación local, ya que las modificaciones que se están produciendo en la estructura social y productiva contribuyen también a poner nuevamente

${ }^{17}$ S. BERger y M. PIORE, Dualismo economico e politica nelle società industriali, Bolonia, 1982. 
en marcha la situación política. Estudios preliminares estiman que, en cada una de las tres últimas consultas políticas y administrativas, un elector de cada tres ha cambiado el sentido de su voto ${ }^{18}$.

Una mirada a la historia del gobierno local permite descubrir dos fechas importantes que definen la situación: 1975, año de la llegada al Gobierno de las izquierdas, y 1985, año de exclusión de los comunistas y de constitución de una coalición pentapartido con alcalde socialista. Lo recordado hasta ahora (electorado móvil, alternancia de gobierno) son datos que de por sí definen elementos de modernidad del sistema político: dentro de una cultura política rígidamente definida en la sociedad, los votos de opinión y de cambio basados sobre cálculos y valoraciones entre opciones alternativas parecen los más extendidos, mientras que no se generalizan los simples votos de pertenencia, sin valoración de las propuestas políticas, basados sólo en la posición social del que vota. Sin embargo, en el caso de Turín, estas características son más síntomas de presiones y demandas que emergen en las confrontaciones con la política que indicadores de un sistema político que ha encontrado un espacio propio, definido por todo lo que es necesario en el interior de la formación social.

Las carencias de la política se advierten mirando en otras direcciones, una vez definido el espacio teórico de la política en la nueva fase abierta para la sociedad y que en estos aspectos no admite retrasos. El punto teórico es la necesidad de funciones específicamente políticas para el Gobierno y la regulación de la sociedad y de la economía, acordes con una situación de intereses muy diversificada y con un ambiente general poco previsible. El mercado se revela como un mecanismo importante y renovado de regulación y como un marco para muchas interacciones posibles; a su vez, la nueva organización permite equilibrios entre orientaciones propiamente organizativas a priori y salidas interactivas a posteriori. El cambio político es el marco interactivo más complejo, necesario para hacer de bisagra entre economía y sociedad, para funciones de gobierno donde los demás mecanismos resultan insuficientes. Sólo la incapacidad para usar debidamente este instrumento puede exagerar el alcance del mercado o de la organización y generalizar el uso de estos instrumentos para funciones que les son impropias. La aplicación de una política moderna requiere, además de la institucionalización del cambio político, el establecimiento de enfoques y proyectos capaces de propiciar una identificación la suficientemente estable y compartida, con objetivos de mayor alcance. Una cosa implica la otra. El cambio es la forma moderna de la interacción política, y la identidad es un producto que se construye cada vez más tomando como punto de referencia a la política.

${ }^{18}$ P. CERI y E. SaCComani, «La mobilità elettorale a Torino negli anni '80», ponencia presentada en el coloquio Cómo cambia Turin, un análisis a través de la movilidad electoral, Turín, 1986. Véase también, en el mismo coloquio, E. MARRA, «I flussi elettorali nei quartieri torinesi: alcune ipotesi interpretative e alcune incongruenze mètodologiche». 
Una vez definido así el espacio teórico de la política, nos encontramos ante las dificultades derivadas de la formación turinesa. Estas dificultades son de orden estructural y cultural. Las primeras tienen que ver con la escasa diferenciación entre sistema político y sociedad civil. Para que la política pueda desempeñar su función es preciso que se dictancie, por así decirlo, de los intereses sociales. Esto es difícil de por sí en una situación en la cual las decisiones de inversión de una sola gran empresa pueden condicionar de manera decisiva todo el orden social de la ciudad. Por evidencias extraídas de trabajos de carácter histórico, sabemos que hay un prolongado período en el cual no es lícito hablar de una verdadera autonomía de la política con respecto a la economía. El Gobierno de izquierda va aumentando progresivamente su espacio de autonomía, pero, además del problema de cultura política, al que nos referiremos más adelante, subsiste la situación de un campo político demasiado invadido por el poder económico.

La segunda dificultad tiene que ver con la cultura política arraigada en Turín. En los años de gobierno de izquierdas resulta un «déficit de cultura de gestión y administrativa», como alguien ha dicho. El impulso inicial y las realizaciones, por ejemplo, en el campo de los servicios finalmente no se concretan con «una cultura administrativa a la altura de las nuevas responsabilidades de gestión o con una cultura de las instituciones» ${ }^{19}$. Esta endeble capacidad de gestión no puede achacarse sólo a la izquierda. Es algo que, por diferentes vías, se arrastra de muy atrás y que, además, tiene que ver con la formación social de la gran organización. El ambiente de la gran organización da lugar a una cultura de radical oposición. En ambos casos, no se trata de una cultura negociadora, o sea, de una disposición hacia los comportamientos interactivos, de racionalidad procesual y limitada, en los que se basa el intercambio político moderno. A todas luces, falta una cultura del «contrato», limitado y válido en virtud de su propia estipulación, entre sujetos autónomos que se reúnen bajo una perspectiva definida, reconociéndose en su autonomía. Más que a la organización, el contrato está culturalmente vinculado al mercado, y sabemos que éste apareció en Turín en época muy reciente y de una manera muy embrionaria. Puede que ésta sea la clave para aclarar muchos aspectos de las orientaciones y de las prácticas políticas no sólo en lo que respecta a los resultados finales de escasa cultura de gobierno.

Desde los tiempos de la protoindustrialización local, la cultura de la organización influye en la determinación de una sociabilidad limitada de los turineses y, tal vez, de ciclos culturales de sostenida calma y de momentos de fuerte conflictividad, factores que no favorecen, por cierto, el pragmatismo político. Pero es probable que la falta de una cultura del mercado, y del con-. trato, se observe también en muchos inmigrantes de la campiña meridional,

19 G. Berta y S. Chiamparino, «Lavoro industriale e azione politica», en Sisifo, núm. 7, 1986. 
salidos de circuitos comunitarios más o menos modificados, regulados por el principio de la reciprocidad. Teniendo en cuenta todo esto, ¿es arriesgado vincular también a la falta de una cultura del contrato, en una sociedad con poca experiencia de mercado, el comportamiento de administradores públicos que acabaron en la cárcel? Los antropólogos describen la situación cultural que se determina en contextos que aún no han tenido experiencias de mercado y que de pronto se abren a este tipo de relaciones económicas. En estos casos, todo lo que no pertenece a la experiencia precedente se mezcla de una manera confusa en el mismo plano: hurto, rapiña e incluso el mercado. ¿Cómo no comprender, entonces, que, en una realidad caracterizada hasta hace poco por valores burocráticos y de fidelidad y en la que se abre de repente la posibilidad de juegos interactivos, unos administradores maniobreros, que buscan espacios de autonomía y que no han interiorizado previamente una moral del mercado, definan la escena política como tierra de nadie para sus correrías en busca de recursos?

El intercambio político implica reglas de mercado más complejas y es más fácil desarrollar la capacidad para usarlas y respetarlas si existe una experiencia precedente no sólo de organización, sino también de mercado. Todo el que proviene de una cultura de la organización tiende a retraerse del intercambio político definiéndolo en función de su patología como intercambio de clientela, o practicándolo como tal.

A pesar de todo, Turín está evolucionando hacia una sociedad más compleja, y acabará por reconocer los problemas del Gobierno de intereses muy diferenciados. Está llegando a ella con pocos recursos en el plano cultural, y en condiciones estructurales difíciles. El problema que se plantea es, pues, saber qué tiempo se necesita para estas adaptaciones y qué estrategias hacen falta para mejorarlas, porque la conclusión a la que hemos llegado es que en Turín en ningún momento se ha aprendido realmente a hacer política. Es indudable que, después de todo este análisis, no tenemos los elementos para responder a estas preguntas. Por otra parte, se trata de un problema político más que analítico. No obstante, tomando como base las observaciones y argumentaciones hechas, estamos en condiciones de subrayar tres puntos que parecen cruciales para realizar una transformación de la política.

El primero tiene que ver con la construcción de los sujetos politicos en un sentido lato del término. El sindicato se encuentra en dificultades; otros intereses buscan formas de representación autónoma en el panorama condicionado por la gran empresa; los partidos están aprendiendo a hacer política a sus expensas, buscando una nueva legitimación tras la cuestión moral; se constituyen formas asociativas de índole diversa y es necesario que tengan posibilidades de desarrollarse. La difusión de los sentimientos de hostilidad o de suficiencia en las confrontaciones de la política resultaría perjudicial en este momento, y más aún lo sería cualquier intento de bloquear o dificultar la institucionalización de las representaciones. Del mismo modo que no es po- 
sible una interacción rica, con división por especialidades del trabajo entre las empresas, sin empresas autónomas y fuertes en el mercado tampoco puede haber intercambio político sin unos sujetos del pluralismo constituidos y reconocidos, y todo lo diferenciados que requiere la situación.

Muchos elementos nos han permitido observar que en apariencia no se dan fuertes tendencias espontáneas de movilización, capaces de comprometer desde la base a muchas personas en direcciones sinérgicas ${ }^{20}$. Por consiguiente, en nuestro caso cabe pensar en formas de movilizaclión en cierta medida organizadas, no totalizadoras, pero de envergadura, de acuerdo con proyectos preparados y gestionados según reglas claras, que combinan de diferentes maneras, de acuerdo con los casos, el uso del intercambio político, del mercado, de la organización e, incluso, de la reciprocidad. Tal vez hablar de proyectos interactivos cuando faltan sujetos bien institucionalizados y autónomos parezca un sin sentido. Pero lo cierto es que, en muchos casos, el proceso de movilización avanza a la par del crecimiento y del fortalecimiento de los sujetos. Por lo tanto, debe quedar bien claro que usamos la palabra movilización en un sentido moderado del término que se define de distintas maneras de acuerdo con el contexto de la acción, y no para indicar un proceso omnicomprensivo y con pretensiones hegemónicas.

Las últimas observaciones nos llevan a las bases sociales de la política. Se trata de la cuestión de las alianzas sociales y de las coaliciones de intereses que pueden orientar las grandes líneas de la política local permitiendo recuperar cierta estabilidad y unidad incluso en la diversidad de las combinaciones contractuales, de acuerdo con las distintas mesas. Puede que éste sea el aspecto más complicado del problema, que corresponde a la función más delicada de la política, que no consiste sólo en ayudar a la organización de las mesas de contratación, sino también en contribuir a establecer un clima de confianza capaz de convencer a los actores para que renuncien a ventajas de corto alcance por estrategias de mayor aliento. Más allá todavía está el hecho de que una coalición relativamente estable debe ser capaz de garantizar las decisiones políticas. Recordemos que los planes interactivos, de racionalidad limitada y a posteriori, sólo representan un polo de la organización de los sistemas; en el otro polo está el proyecto organizativo sinóptico. Por lo general, los sistemas sociales concretos se afirman en una situación intermedia. El hécho de que se reconozca la necesidad de una fuerte tendencia hacia esquemas inter-

${ }^{20}$ Sólo puedo citar aquí una investigación que muestra a las claras la dificultad de movilización espontánea. Se trata del estudio de G. Bonazzi sobre la formación de cooperativas entre obreros expulsados de la fábrica en los últimos años, en la provincia de Turín. La investigación es importante porque documenta no sólo lo exiguo del fenómeno, a pesar de algunas condiciones que aparentemente debían favorecerlo, sino, sobre todo, la complejidad cultural y organizativa de los procesos cooperativos en un área caracterizada por tradiciones de grandes industrias y de movimientos de oposición que son reflejo de ella. Véase G. BoNAzZI, «Spontaneità ed assistenza nello sviluppo cooperativo: una ricerca in un'area metropolitana in crisi occupazionale», en Quaderni di Sociologia, núm. 6, 1986. 
activos en la nueva condición contextual no significa que se excluya la necesidad -en ciertos casos y en situaciones de impasse- de decisiones que anticipen soluciones, proponiendo objetivos coherentes.

Volviendo a Turín, por un lado, tenemos los grandes intereses económicos, que cada vez se diversifican más, y ya no sólo en el interior de la industria. Basta pensar, por ejemplo, en la importancia cada vez mayor de los centros financieros y bancarios. Por otra parte, se produce un cambio de la estructura social, aunque en direcciones que todavía no están muy claras. En términos muy generales, se puede decir que la disminución de los operarios desplaza la atención sobre las clases medias. Pero lo que aún no se sabe a ciencia cierta es qué hay en el medio, y si está realmente en el medio. La cuestión de las coaliciones para políticas específicas implica escoger qué hacer, con quién hacerlo y a qué costo. Esto significa también ventajas y costos diferenciales: combinarlos y cambiarlos es el juego de la política. Cuando las ventajas y los costos se apartan de una manera acumulativa y continuada, se reducen las condiciones generales de la política interactiva.

Las líneas señaladas constituyen una posibilidad capaz de favorecer el desarrollo económico y la modernización social de la formación turinesa. En realidad, también son posibles compensaciones de bajo perfil que, indudablemente, comportarían una escasa valoración de los recursos disponibles y problemas sociales renovados. La falta de funciones políticas de conexión, y de sostén, y de infraestructuras, repercute sobre la posibilidad de aprovechar las ocasiones económicas. Sin embargo, la economía podría ajustarse por su cuenta, con el juego de organización y mercado, que ha vuelto a cobrar movilidad en el territorio, descargando hacia el exterior los problemas y las ineficiencias residuales. Las compensaciones de bajo perfil -que no excluyen la rentabilidad de las empresas claves- significan, no obstante, renunciar a hacer frente a problemas graves como la desocupación.

De todo lo dicho se desprende que la política podría ser también, y de manera particular en Turín, un grave cuello de botella para el desarrollo. En un último análisis, la cuestión vuelve a la escasa diferenciación de la formación social metropolitana y a las vías para ponerle remedio. ¿Es posible salir del impasse de la organización y de la política de orientación totalizadora? ¿Cómo conseguirlo plenamente si para ello son precisos recursos culturales que no pertenecen precisamente a la situación de origen? Las huellas de los largos períodos históricos nos remontan a muy atrás: Turín ya era regulada por la organización mucho antes de que naciese la Fiat, cuando la Corte gobernaba con la burocracia y el ejército y la ciudad crecía piedra a piedra. Pero no hay que dejarse llevar por el juego de los largos períodos. Entre dos fases de gran organización, Turín vivió, a comienzos de siglo, una época de mayor diferenciación social, con una economía diversificada y en crecimiento, con un gobierno local autónomo y fuerte, empeñado en crear infraestructuras económicas y sociales eficaces y en un juego de negociación e interacción entre 
las representaciones en vías de constitución; en suma, un panorama autónomo y diferenciado ${ }^{21}$. Fue aquélla una época de gran dinamismo, de experimentación económica y social «moderna». No obstante, no tardó en comenzar la experimentación de otra forma de modernización, que necesitaba quemar etapas para recuperar el tiempo perdido y que, por la forma en que se produce la concentración conseguida, acabó imponiendo a Turín una pesada tarea que la ha marcado. El intervalo de comienzos de siglo hizo surgir modelos de comportamiento que no eran típicos de la sociedad preindustrial de un reino fuertemente centralizado. La sociedad turinesa no se consolidó sobre esa base, y consideró más propio repetir el camino de la gran organización y la racionalidad sinóptica. Puede que la diferencia esté en que, hoy en día, cualquier forma de modernización y desarrollo impone la necesidad de modelos interactivos.

(Traducido por Ema R. Fondevila.)

${ }^{21}$ V. Castronovo, Il Piemonte, Turín, 1977. 